\title{
Graduation project in designing an Educational Software using ADDIE design model
}

\section{Abdullah Abdulrahman Aldosari}

Kingdom of Saudi Arabia

King Saud University

College of Education

$$
\begin{aligned}
& \text { or. or } 11 / 0 / 1 \\
& \text { prol }
\end{aligned}
$$

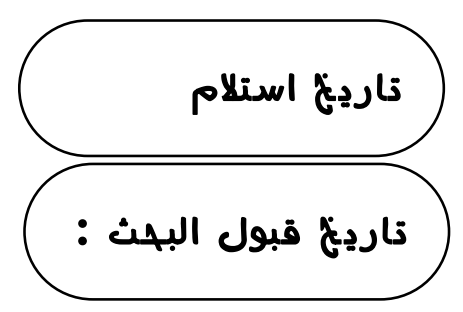




\section{Introduction}

Education is the first building block of civilizations. It therefore became necessary for specialists to pay attention to its aspects, as they imposed upon themselves the burden to support the futuristic vision. With the explosion of the information revolution and the widespread of computers, technical and educational experts put up what is called "educational programs" as a means to break the students' intellectual deadlock, to rely on themselves in general and to help with the transition from education to learning. Since there is a need for continuous development of the educational process, it was necessary to include the educational programs, so education by computer will play an important role in education and training during the remainder of this century (Ellington 21:2001)

Educational programs will not achieve its objectives unless there is a clear follow-up strategy, and continuous studying of its benefits for the students; to ensure its quality and validity in achieving the results effectively. Despite the great optimism, this is still theoretical, As these programs are not widely used on the ground. This is clearly evident in clinging to traditional methods and relying on verbal presentation and indoctrination.

Students' failure to rely on educational programs does not mean that we can judge with failure on the outputs of education. The diversity of sources has an active role in motivating students to learn. Although all educational subjects will have a share in these programs, languages have the largest cut, which needs to move away from scientific droughts and to the thrill and pleasure, not to mention the need for the student to move to the tangible and link the facts. Therefore, attention should be given to teaching techniques when teaching of English language, and to diversify as much as possible in tangible means, materials and educational games, which will help to communicate information and new knowledge of the student. (Beno Hani, 2010:77)

\section{Project problem:}

The problem of the project lies in the students's weakness in English and the drop in their level in the due to the lack of diversification of the methods of presentation, and we conclude that the main problem of the project is the extent of the middle school students' benefit from the additional educational programs for English language.

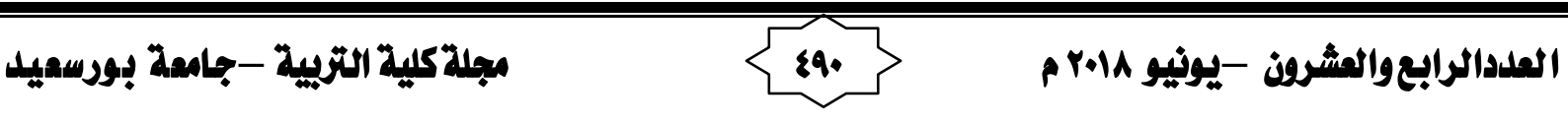


Project Objective:

This project aims to:

1 - Highlight the important role of educational programs in learning

English in middle school.

2. The use of English language programs by middle school students.

3. Improve students' learning levels by using educational programs.

\section{Project importance:}

The project's importance lies in the following points:

- Educational experts trend to design educational software.

- To enrich the educational materials using modern teaching methods.

- Creating a learning environment that takes into consideration individual differences.

- Achieving the thrill of learning English.

- Develop the individual learner's skill.

- Developing new methods for teaching English language.

- Saving time and effort for the teacher, and providing the lesson in a simplified way.

\section{Project terms:}

Educational program:

(Mazen, 2010) defines educational program/software as the educational material that is prepared and programmed by computer for learning.

\section{Model:}

A model is a mental image that helps us understand something we can not see or experiment with directly. (bel \& Demmin, Dorin, 1990)

\section{Educational Design:}

Educational design is the way of selection and arrangement of educational materials in a way that helps students learn more efficiently. (1992, Merill, Tennyson \& Posey), and defined by (McGriff, 2001) as systematic plans by the educational designer to create a workshop, curriculum, program, or a training course. (Mentioned in professional A Development Program for Converting Classroom Course into (2007, Hybrid Courses) 
Previous studies:

Secondly: Foreign Studies:

(Al Farr, 1994) study demonstrated that the computer environment in teaching and learning, that is used to communicate and interact between Learners, creates positive attitudes as an educational tool on the one hand, and towards the subjects they study on the other, which drives them to learn, and thus raise their understanding when learning mathematics. (Al - Mutairi, $1419 \mathrm{AH}$ ) study on the impact of using a computer software in studying science on the achievements of sixth grade primary students: - Methodology: Experimental

- Sample: Teachers and students in the sixth grade

- Tool: Identification and test achievement

- Main results:

There were statistically significant differences at the level of $(\mathbf{P} 0.05)$ in the average students' achievements favouring the experimental group at the two stages of remembering and understanding of the Bloom classification, while there were no differences in the application phase.

The researcher recommended the following based on the results he achieved:
A. Expanding the use of computer software in the teaching of science.
B. Develop a phased implementation plan to provide the required computers and softwares that suits the nature of the science curriculum.
C. Meeting the technical and scientific standards in the used software.

The study of ( Al Badr $1422 \mathrm{AH}$ ) entitled "the effect of computer in training on solving mathematical problems in developing the ability of female students in the mathematics department in the Faculty of Education", aimed to study the effect of computer in problem solving training and the formation of positive attitudes towards mathematics, The researcher conducted a pilot study for this purpose, the most important results of the study were:

A. There are statistically significant differences between the average score of students who used the computer in training to solve mathematical problems, and their positive trend towards mathematics.

B. There are statistically significant differences between the average score of students who used the computer in training on mathematical problems before and after the experiment in favour of the post-test.

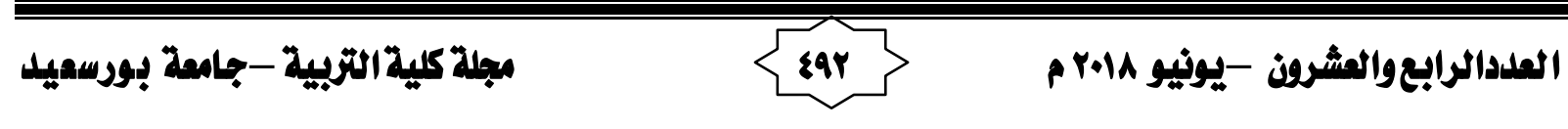


A study conducted by (Zela'y 1428 Afr) on the impact of one computer program on learning English grammar for students in the first grade secondary school in Jeddah. The study was based on a semiexperimental approach, where the study was applied to a sample of 42 students in the first grade of secondary education, which was divided into two experimental groups, each consisting of (22), they studied the grammars using computer as a learning tool. And a control group consisting of (20) students studied the same grammars using the traditional methods based on verbal presentation and the use of textbook, blackboard and coloured pens. The study tool was a an achievement test that has been verified before its actual application to the two study groups.

Results:

The results showed the following:

1. There are statistically significant differences in memorisation between the average achievement of students in the experimental group and the average achievement of students in the control group in favour of the experimental group.

2. There were statistically significant differences in understanding between the average achievement of students in the experimental group and the average achievement of students in the control group for the experimental group.

3. There were statistically significant differences between the average achievement of students in the experimental group and the average student achievement in the group.

A study conducted by (Al Dabbasy, 1426 AH) aimed at finding out the effect of using computer software in teaching English on the achievement of sixth grade students in Riyadh. The results were:

1. There are statistically significant differences at $(P 0.05)$ in favour of the experimental group, which confirms the positive impact of the used educational software to raise the level of achievement of students in the Arabic language course.

2. There are statistically significant differences at $(\mathbf{P} 0.05)$ between the pre and post-application on the experimental group, regarding the level of achievement of the sixth grade pupils, in the English language course in favour of the post-application.

(Al Otaibi, 2003), conducted a study on the impact of using one of the computer programs on learning the English language on the achievement of secondary school students in Riyadh.

The sample of the study consisted of 60 female secondary school students who were randomly selected.

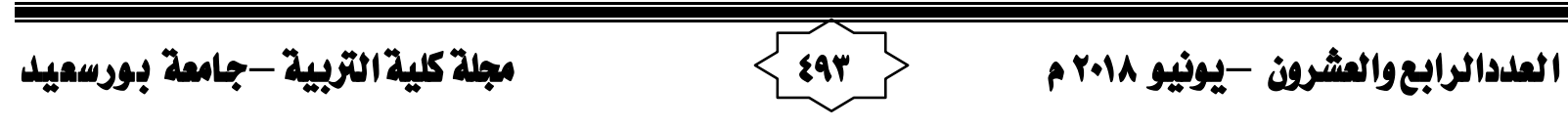


The results of the study:

1. Acceptance of the first hypothesis that is there is no significant differences at (P 0.05) in the achievements of English language between the control and experimental groups at the level of memorisation, understanding and application.

2. Acceptance of the fourth hypothesis that is there is no statistically significant differences at $(P$ 0.05) in the achievement of the English language between the control and experimental groups in the overall post-test achievement.

(Al Dailig 2003), conducted a study to test the impact of a locally produced software on the achievement of intermediate second-grade students in mathematics.

Sample: 70 female students, divided equally into two groups, an experimental group and a control.

Results:

1. There were no statistically significant differences in the average student achievement among the experimental that used the computer software and the control group that studied in the traditional way one the three cognitive levels: remembering, understanding, application.

2. There were no statistically significant differences between the average achievement of the students in the experimental group and the control group in the overall achievement test.

3. There is a difference in the time taken to learn "applications on relative numbers" between the experimental group and the control group in favour of the experimental group.

Secondly: Foreign Studies:

(Shashann 1995), conducted study about a computerised software in mathematics that proved its effectiveness in this subject.

(Kirk \& Patrick 1998) confirmed the success of the experiment about students' attitudes as an educational tool in mathematics.

(Chang 2002) conducted a study aimed at understanding the impact of using teaching computer software that uses problem-solving to improve learning outcomes in teaching science. The results of variables analysis showed that the students who studied according to the method of problem solving using computer have obtained higher grades.

Proposed Project Methodology:

This software will be based on three axes:

1. Preparation of a learning design model using the general model ADDIE.

2. Preparation of a scenario for the educational software.

3. Implementation of the educational software.

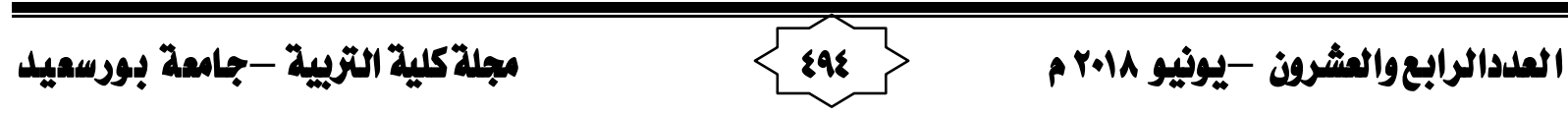


Project limits:

Objective Limits:

The program will be used to study "the daily life" lesson from the seventh module.

\section{Spatial Limits:}

This program will be applied to the students of Imam Al-Nisabouri school in Al Rawabi district.

Time limits:

The designer will implement the program in the second semester of the academic year 1432-1433 AH.

\section{Implementation mechanism:}

This software is based on a self-learning method, where the software designer divided it into four lessons. Each of these lessons has a behavioural objective, and takes into consideration a logical learning sequences, in which the student passes from easy to hard.

The learner moves between the lessons by presenting the content at the beginning of the tutorial in the following sequence:

- Lesson 1 (activities): The learner connects the image, pronounces the word with mouse hover over the word, and then answers the questions that accompanies the lesson.

- Lesson 2 (jobs:) The learner connects the image, pronounces the word with mouse hover over the word, and then answers the questions that accompanies the lesson.

- Lesson 3 (roles and jobs:) The learner hovers the mouse on the image to listen to the pronunciation, then clicks on the image to show the definition of the word, and then answers the questions that accompanies the lesson.

- Lesson 4 (conversation:) The learner listens to the conversation and then answers the questions that accompanies the lesson.

\section{ADDIE Model:}

The ADDIE model is a systematic educational design that consists of five stages: analysis, design, development, implementation and evaluation. Each stage has results that can feed up the next step sequentially. (Knowledge and webliography, 2001) 


\begin{tabular}{|l|l|}
\hline Lesson & Procedure \\
\hline activities & $\begin{array}{l}\text { Recognize some daily life activities. } \\
\text { For } \\
\text { Example, (spend time with family, do } \\
\text { housework, study.... etc). Then, do the } \\
\text { exercise. }\end{array}$ \\
\hline Jobs & $\begin{array}{l}\text { First , some jobs that can be used to } \\
\text { recognize } \\
\text { people . e.g. ( a secretary, a journalist, } \\
\text { a } \\
18 \text { Daily Life } \\
\text { policeman.... etc). }\end{array}$ \\
\hline $\begin{array}{l}\text { Jobs and } \\
\text { roles }\end{array}$ & $\begin{array}{l}\text { The student listens and repeat the } \\
\text { conversation about jobs and roles. }\end{array}$ \\
\hline $\begin{array}{l}\text { General } \\
\text { questions }\end{array}$ & $\begin{array}{l}\text { The students answer the general } \\
\text { questions }\end{array}$ \\
\hline
\end{tabular}

Analysis of educational objectives:

The educational objectives of this unit are:

1. Talk about daily activities.

2. Talk about work.

3. Listen to a conversation about daily activities.

Task Analysis:

The educational task is the skill that the student will learn at the end of this lesson:

- Identify some daily activities.

- Identifying the names of professions.

- Identify the role of the employee in his profession.

- Listen to vocabulary pronunciation.

- Listen to a conversation between two people.

- Answer the given questions.

Target group analysis:

The characteristics of learners and their age range are recognized before the introduction of the educational software. This program is designed for students in the second grade of middle schools, aged between 13 years and 14 years. At this stage, the social and educational level of the

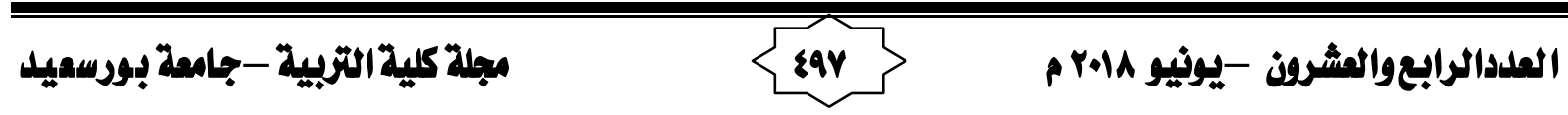


students as weil as their previous experience is determined making it easier for the designer to determine the appropriate content, objectives, teaching methods and tools appropriate for their age.

Adolescence is a long period, divided into three stages. What concerns us in this program is early childhood, which touches the age group, from (11) to (14) years A period of rapid changes towards puberty.( (Al-Adhami, 2007: 59)

With the apparent progress of mental development, changes in psychological and mental characteristics, and the principles of cognition and attention of the adolescent, it is presumed to be able to distinguish activities, the importance of work and the knowledge of professions to prepare the student for a practical life. The characteristics of adolescent mental development at this stage include:

1. The general level of intelligence grows rapidly, mental abilities begin to differentiate, and the student's intelligence reaches its maximum level at the end of this stage.

2. The rate of achievement is apparent, and the student prefers some subjects over the others.

3. The ability to learn skills and acquire information increases.

Analysis of the educational environment:

Educational resources and constraints:

1. Interactive blackboard.

2. Projector (Data Show).

3. Computer .

4. Headphones.

5. Educational software floppy disk.

The classroom is the room in which the lesson will take place.

The class duration: 45 minutes.

Human resources and constraints: teacher and students

Administrative resources and constraints: School management

Obstacles:

- Power outages

- Hardware malfunction

- Floppy disk corruption

Alternatives to overcome the previous problems:

There are alternatives as follows to avoid and to compensate for these problems:

- A personal computer that runs on a battery and is displayed through it.

- Other storage media used to store a backup copy of the content of the software, such as:

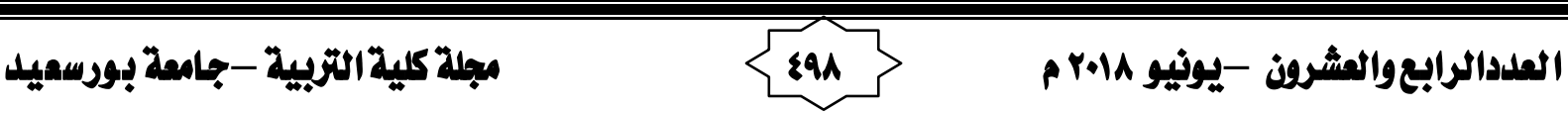


(CD) and (flash memory)

Secondly: Design phase:

Kearns believes that if the analysis stage is the basis of educational design, the design phase is the architecture (Kearns, 2010: 71). This step includes a description of how the design document will be reflected in the needs analysis (Cox, 2010)

The design phase includes the following:

- Defining performance objectives (procedural objectives) based on lesson objectives and learning outcomes in measurable terms and criteria for successful performance of each goal.

- Determine the appropriate appraisal for each goal.

- Determining teaching strategies based on goals (Saleh, 2003)

The learning strategy will be determined by learning software.

Behavioural Goals:

Behavioural objectives are one of the main components of the educational curriculum. They are an important pillar in the process of teaching and learning in class, when they are defined as observable and measurable outcomes, an objective that all educational institutions require to achieve either in whole or in part. (Al-Nour, 2008: 29). Robert explained the reason behind developing the behavioural goals, where he pointed out three benefits $\mathbf{f :}$

1. Adopting a good basis for selecting the educational content.

2. Provide learners with the means that organise their efforts and activities to achieve the purpose of education

3. Allows you to specify whether the target has been achieved.(Bastable, 2008, 388)

The objectives will be formulated as follows:

At the end of the program' the student will be able to:

1. The student knows about $100 \%$ of the daily activities.

2. The student knows some occupations by $100 \%$.

3. The student knows the role of each employee in his profession.

4. The student talks about occupations and daily activities.

Appropriate appraisal of previous objectives

The student answers the exercises at the end of each lesson and then moves to the final appraisal by solving the general questions at the end of the program.

Teaching strategies :

Singh \& Rana (Singh \& Rana, 2004: 3 ) defines the education strategy as what the teacher seeks which aims to establish the interaction between the teacher and the students, the subject, or the combination between many of these three dimensions.

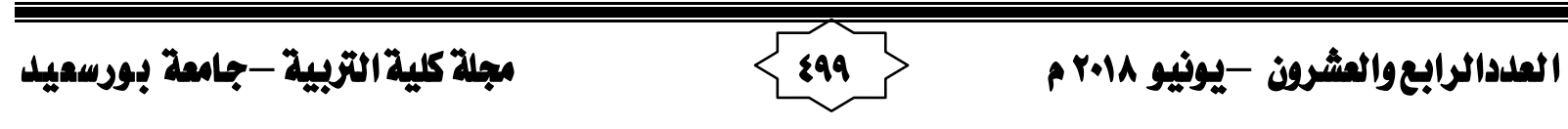


It is a set of actions, activities, and methods chosen by the teacher or planned to follow one after the other, sequentially using available resources, to help his student master the objectives (Al-Hilah, 2008: 149).

This program is based on the self-learning method,which is divided by the designer into four lessons. Each of these lessons has a behavioral objective, taking into account logical learning stages, in which the student sequences from easy to hard.

A set of unit images appears on the Home screen. On this screen, the student moves to the contents of the unit or information about the educational program. A learner can move to any lesson through the contents list. After completing the lesson, the learner can solve the exercises related to each lesson by clicking on the (Question) icon at the bottom of the screen. After completing all the lessons, the student takes a final assessment of his performance by solving the general questions, consisting of seven questions. The first consists of three paragraphs. The learner clicks on the odd word. The second question consists of four paragraphs. The student selects the correct answer by clicking on True or False mark.

Preparation of teaching aids:

- Computer to display the program: The teacher explains how to use the educational software.

- Educational program: It contains sounds and expressive images that are compatible with the properties of learners.

Initial planning of the program scenario:

The first step before writing the script is a sketching the screens that will be included in the program and their sequence, making it easy to build coherent program screens. The number and type of screens are determined by the program type, which may be interactive, training, simulation, presentation, printing or game software. (Al Saleh, 2003). (Wales, 2009) points that the scenario is the starting point for a product cycle that begins with the development of the prototype, and aims at developing products that fit this scenario.

In the following figure, the design model of the educational programming scenario:

\begin{tabular}{|l|l|l|}
\hline Screen design & Notes \\
\hline \multirow{2}{*}{} & Appearance & Audio \\
\cline { 2 - 3 } & & \\
\cline { 2 - 3 } & Student activity: \\
\hline
\end{tabular}

Flowchart for software:

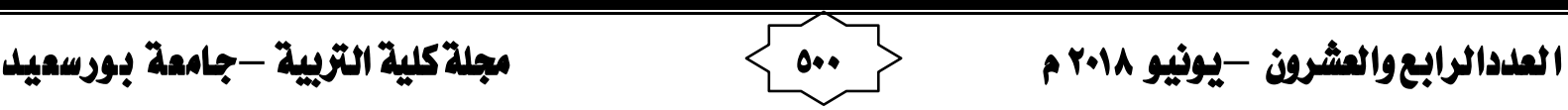




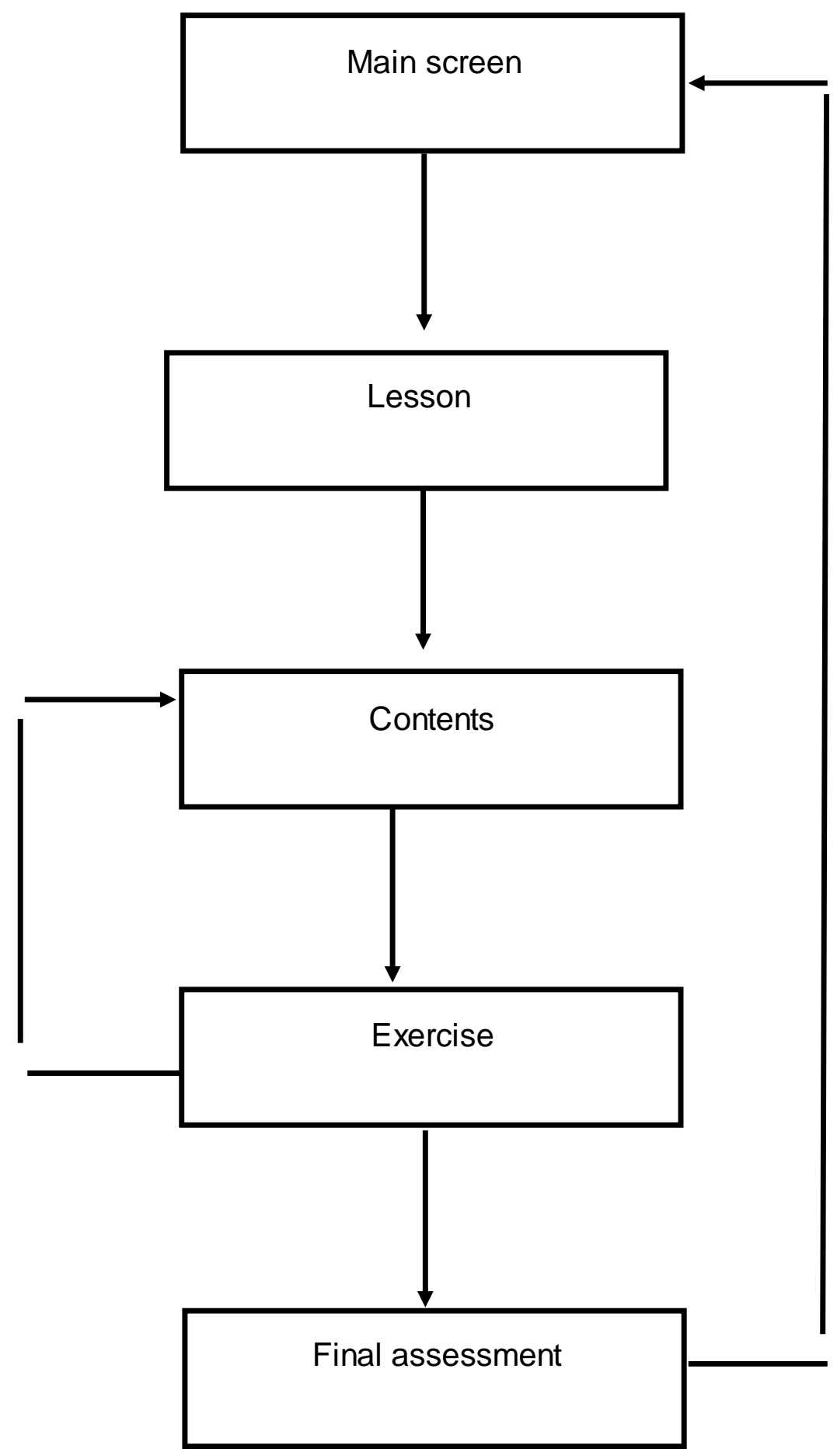

Thirdly: The stage of development:

The development phase refers to the actual creation, content production and learning materials based on the design stage.

The designer chose the means and facilities suitable for the general goals and objectives for the study of daily life, where the images were obtained through the web, and since no sound clips are appropriate, they have been recorded by the designer. The student can also refer to enrichment links at the end of the program 
The following methods have been used:

a . Computer hardware.

B . A CD-ROM containing the software produced by the designer.

C. User's Guide

2. Production of non-available materials:

Some of the images on the web were not good enough; so some of them were processed using the image processing program (Photoshop)

Fourthly: The stage of implementation:

At this stage, the designer evaluates the software, and this is done in three stages:

Stage 1: Individual Application:

The software is applied to a small sample of learners independently.

Stage 2: Application stage in small groups:

The programmer will apply the software to fifteen students in the second intermediate grade.

At these two stages, the programmer implements the software itself, taking into account the learning environment, in order to know the effectiveness of educational materials, strategies and evaluation materials.

Stage 3: Field application phase: The program will be implemented at this stage on thirty students from the same grade. The programmer supervises the teacher if necessary.

Fifthly: The evaluation phase:

The evaluation stage is the final stage in the management of educational design projects, where the review of the formative and final evaluations is completed and the project is completed.(Cox,2010)

Firstly: Formative evaluation:

Formative evaluation occurs during the design process, especially during the design and development stage to ensure that the learning objectives and the learner's needs are met.(Koohang \& Harman, 2007:368)

This program will be presented to a sample of outstanding teachers in the Department of Education in Riyadh,and a group of students to take the final feedback, and modify the errors before their final use.

The questions will be as follows:

- Lesson one: Activities:

Choose the right answer. 


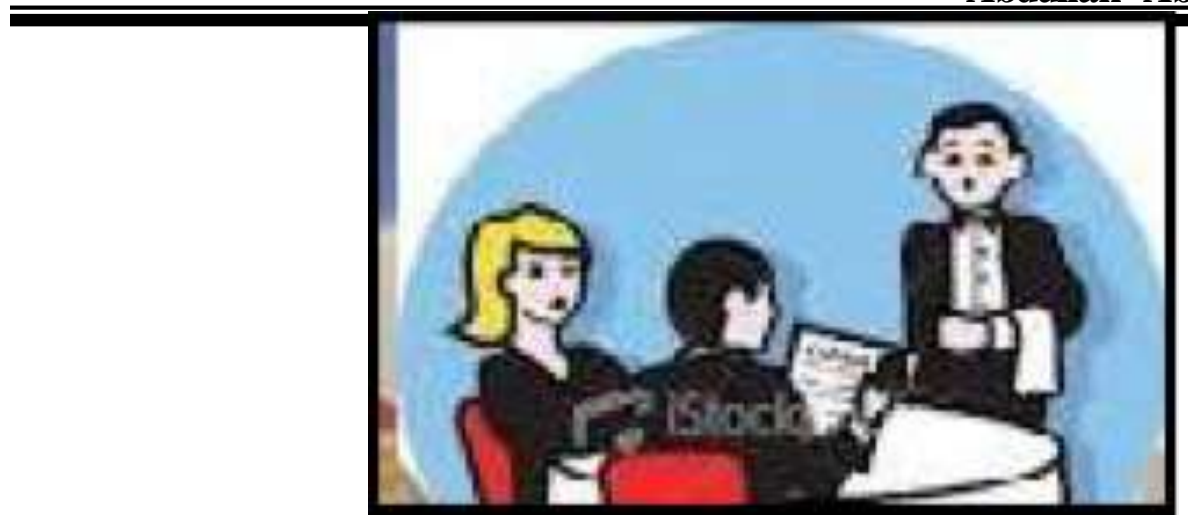

- Eat out

spend time with family

visit relatives

* Lesson two: Jobs:

Choose the right answer.

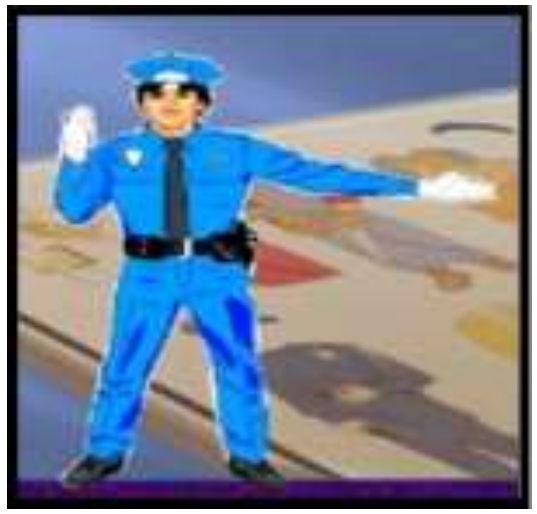

Waiter journalist policeman

* Lesson three: Jobs and Roles:

Choose the right answer. writes letters.

policeman secretary

journalist

- Lesson four:Conversation:

Choose the correct answer

What does Ali do?

secretary

hairdresser

journalist

What does Faisal do?

patient

doctor

writer

A policeman

Controls traffic

looks after children

serves food 
Secondly: Summative evaluation:

The final review is conducted during this final stage of the design process to test the effectiveness of the final learning models, and to review the overall success of the educational design process (Koohang \& Harman, 2007: 368)

At this stage, the extent to which the educational objectives of the program are achieved is verified by presenting comprehensive evaluation questions for the unit.

Q1: Find the odd one out.
1) Waiter
food
2) Computer
letter
restaurant
traffic
secretary
eat out

3) Spend time

journalist

writers

newspaper

Q2: Put true or false.

- Journalist writes for newspaper.

- Waiter serves food.

- Secretary controls traffic.

- An announcer presents news. 
First: Arabic References:

Ellington, Henry. (2001) Production of educational materials: a guide for teachers and trainers translated by Dr, Abdul Aziz

Al-Aqili. Riyadh: scientific publishing and printing.

Al A'zami, Said Rashid. (2007) Scientific Fundamentals of Childhood and Adolescence: Modern and Contemporary Theories Amman: Juhayna for Publishing and Distribution.

Beno Hani, Walid Abd. (2010) Utilisation and employment of educational techniques in the classroom: Amman: Culture World House for Publishing and Distribution, first edition.

Al Jasser, Sarah Jasser. (1426 AH): A study entitled: Individual and collective learning using an educational program, The computer curriculum for the second grade secondary school for girls in Riyadh, Master's degree, unpublished King Saud University, Riyadh.

Al Haila, Mohamed Mahmoud (2008) Design of Education. Amman: Dar Al - Massira Fourth edition.

Al Khathlan, Mansour Zaid. (1427 AH) A study entitled: The extent of achieving the objectives of introducing the computer in middle school curricula from the point of view of the principals, supervisors and teachers. Master's degree, unpublished King Saud University, Riyadh.

Al Dabbasi, Areej Saleh Mubarak. (1426 AH) A study entitled: The impact of of computer software in teaching English on the achievement of the sixth grade students in Riyadh, Master's degree, unpublished King Saud University, Riyadh.

Dailej, Maha Abdullah. (2003) A study entitled: The Effect of Using a locally produced Mathematics Course Software on the Achievement of Second Grade Students in Riyadh City, Master's degree, unpublished King Saud University, Riyadh.

Al Saleh, Badr. (2003) The procedural guide for the educational design of the teachers. Date of entry: 1433/1/24 AH Available through the link http://www.Irc-online.net/library/wp-content/uploads/2010/06/zs.pdf

Al Otaibi, Fatima Abdullah Rashed (2003) A study entitled: The Effect of Using a Computer Software in the English Language on the Achievement of Secondary School Students in Riyadh, Master's degree, unpublished King Saud University, Riyadh.

Al Fayez, Hussein Ahmed. (1429 AH): A study entitled: The reality of computer use by Science Teachers in Secondary Schools, Master's degree, unpublished King Saud University, Riyadh. 
Nour, Ahmed Yaqoub (2008) Educational Psychology Amman: Dara alJanadriyah for publication and distribution.

Al Zalei, Riyad bin Ahmed Ibrahim (1428 AH) A study entitled: The Effect of one of the computer programs on learning English grammars for students in first grade secondary in Jeddah, Master's degree, unpublished King Saud University: Riyadh.

Mazen, Hossam El-Din Mohamed Abdel Muttalib. (2010) Information Technology and its Electronic Media Cairo: Dar Al-Elm wa ElEman for Publishing and Distribution.

Kingdom Teachers Forum. Date of entry: 1433/1/27 e. Available through the link

http: //www.ksa-teachers.com/forums/f183/t-4227.html

Secondly: Foreign References:

Bastable, Susan B. (2008) Nurse as Educator: principles of Teaching and Learning for nursing practice. Canada: Jones and Barlett Publishers, Inc. (3rd ed.)Burger, John M. Webber, Charles F and Klinck Patricia. (2010). Intelligent Leadership: Constructs for Thinking Education

Leaders. Canada: Published by Springer.

Cox. Dorcas M. T. (2010) Project Management Skills for Instructional

Designers: A Practical Guide.USA: iUniverse.

Kearns, Suzanne K. (2010) E-Learning in Aviation. UK: Library of Congress cataloging-in-Publication Data.

Koohang, Alex \& Harman, Keith (2007) Learning Objects and Instructional Design. California: Informing Science Press.

Learning Theories Knowledgebase (2011, December). ADDIE Model at Learning-Theories.com. Retrieved in December 22nd, 2011 from http://www.learning-theories.com/addie-model.html

McArdle, Geri (2011) Instructional Design for Action Learning. USA: American Management Association.

Merrill, M. David. Tennyson, Robert D. \& Posey, Larry O. (1992) Teaching concepts: an instructional design guide. New Jersey: Educational Technology Publication. (2nd ed.)

O' Laughlin, Nancy J. (2007). A professional Development Program for Converting Classroom Course into Hybrid Courses. Paper submitted to the Faculty of the University of Delware in in partial fulfillment of the reqirements for the degree of Doctor of Education with a major in Educational Leadership.

Singh, R. P \& Rana, Gopal (2004) Teaching Strategies. New Delhi: S.B. Nagia.

Willis, Jerry. (2009) Constructivist instructional design (C-ID): foundations, models, and examples. USA: Information Age Publishing, Inc.

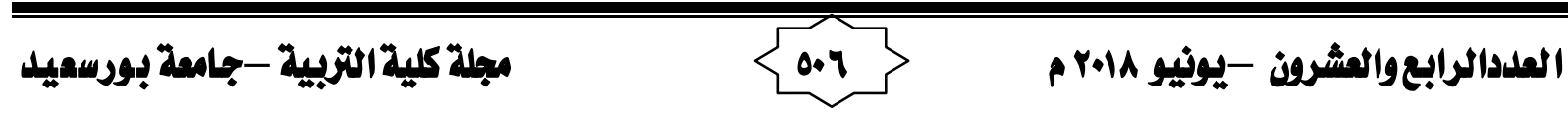

